\title{
Expanding options for retrograde recanalisation of right coronary artery chronic total occlusions
}

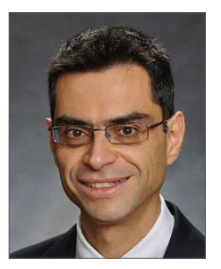

Emmanouil S. Brilakis ${ }^{1}, \mathrm{MD}, \mathrm{PhD}$; William J. Nicholson ${ }^{2}, \mathrm{MD}$

1. VA North Texas Healthcare System and University of Texas Southwestern Medical Center, Dallas, TX, USA; 2. York Hospital - Wellspan Health Systems, York, PA, USA
The right coronary artery (RCA) is the most common target vessel for chronic total occlusion (CTO) percutaneous coronary intervention (PCI), accounting for $44 \%$ of target lesions in the multicentre CTO registry in Japan (J-CTO $)^{1}, 50 \%$ in the European Registry of Chronic Total Occlusion (ERCTO) ${ }^{2}$, and $59 \%$ in the Prospective Global Registry for the Study of Chronic Total Occlusion Intervention (Progress CTO) ${ }^{3}$. The exact reasons underlying this high prevalence are unclear. Possible contributing factors may include the long length that the RCA runs in the atrioventricular groove before it bifurcates into the posterior descending and posterolateral arteries. The poor long-term patency of saphenous vein grafts $^{4}$ in contrast to the excellent patency of internal mammary grafts also results in the native occluded vessel becoming clinically relevant following bypass surgery ${ }^{5}$.

Given the high prevalence of RCA CTOs, strategies for successfully recanalising them are very important to the CTO operator and can be broadly categorised as antegrade and retrograde. Antegrade crossing can be achieved with wire escalation or antegrade dissection/re-entry ${ }^{6}$. A dissection/re-entry strategy can be liberally leveraged in the RCA because possible occlusion of acute marginal branches caused by dissection typically does not cause adverse consequences. Retrograde crossing can be achieved most commonly via collaterals from the left anterior descending artery (usually septal but also epicardial), but can also be performed via saphenous vein grafts (patent or occluded ${ }^{7}$ ), and through ipsilateral collaterals ${ }^{8,9}$ (Figure 1).

Selection of the optimal crossing strategy for RCA CTOs starts with a careful review of the angiogram, ideally using dual injections through large-bore guide catheters ${ }^{6}$. Angiogram review is best done with all members of the cardiac catheterisation team in a highly interactive fashion. Four key questions are asked: 1) where does the occlusion start? 2) how long is it? 3) what is the quality of the distal vessel? and 4) are interventional collaterals present ${ }^{6,10}$ ? Starting from these questions a brainstorming session ensues with initial emphasis on quantity, identifying and writing down all possible crossing options. In the next step the options are ranked in terms of feasibility and safety arriving at the final "plan of attack". The plan is not set in stone, but is flexible and can change at any time depending on new information obtained during the procedure. It is critical to have a pre-procedural plan, or important options may be missed "in the heat of the battle"!

In general, an initial antegrade crossing attempt is preferred for most patients, as use of the retrograde approach is often associated with higher risk $^{11}$ for periprocedural myocardial infarction $^{12,13}$, donor vessel injury, and collateral perforation, that can be very challenging to control, especially in epicardial collaterals ${ }^{14}$. However, in some cases a primary retrograde approach is preferred, especially in cases with proximal CTO cap ambiguity, or poor landing zones secondary to an important bifurcation or a diffusely diseased distal vessel.

Use of the retrograde approach is commonly required for RCA $\mathrm{CTOs}^{15}$. In the ERCTO retrograde registry the RCA represented $70.4 \%$ of all CTO lesions ${ }^{16}$. Retrograde crossing of RCA CTOs is most commonly performed via septal collaterals. Septal collaterals are relatively easy to cross and carry low risk for complications if traumatised, although septal haematomas causing compression

*Corresponding author: Dallas VA Medical Center (111A), 4500 South Lancaster Road, Dallas, TX, 75216, USA. E-mail: esbrilakis@gmail.com 
have been reported ${ }^{17}$. Saphenous vein bypass grafts (SVGs) are also favourable conduits for retrograde RCA CTO crossing with a low risk of perforation. On occasions, retrograde wiring into the RCA after the touchdown of the distal SVG anastomosis can be challenging and may require the use of an angled tip microcatheter such as the SuperCross ${ }^{\mathrm{TM}}$ (Vascular Solutions, Inc., Minneapolis, MN, USA) or a deflectable tip microcatheter such as the Venture ${ }^{\circledR}$ catheter (Vascular Solutions) ${ }^{18}$. Retrograde crossing of occluded SVGs is more successful in recently occluded SVGs with a clear proximal funnelled stump and is usually achieved with a Corsair microcatheter (ASAHI Intecc, Aichi, Japan) and a PILOT 200 guidewire (Abbott Vascular, Santa Clara, CA, USA). The third option for retrograde crossing of RCA CTOs is the use of ipsilateral collaterals, which is an infrequently performed procedure. In this issue of the Journal, Mashayekhi et al elegantly provide a thorough, detailed, and practical description of how to use ipsilateral collaterals for RCA CTO $\mathrm{PCI}^{19}$.

\section{Article, see page 1231}

First, careful attention should be paid to performing optimal coronary angiography. Ipsilateral collaterals often arise close to the RCA ostium or from a separate ostium. Hence, suboptimal visualisation may occur when injections are performed with the catheter deeply intubated. Contrary to standard RCA CTO PCI in which an Amplatz 1 or Amplatz 0.75 guide is used to engage the RCA, a JR4 guide with side holes to allow contrast to fill the proximal RCA directly and indirectly may be a better choice for ipsilateral collateral visualisation and crossing.

Second, the authors demonstrate that ipsilateral collaterals of the RCA are not uncommon; they were present in $30 \%$ of RCA CTOs. The majority of these (66\%) follow an epimyocardial course as opposed to an intramyocardial path.

Third, in Figure 1 of their article, the authors classified and illustrated five types of ipsilateral collaterals based upon their origin and the course of the collateral. Although epimyocardial collaterals as a whole are more frequently encountered than intramyocardial collaterals, when subdividing all ipsilateral collaterals into these five categories, a septal intramyocardial course from the proximal RCA to the posterior descending or posterolateral arteries is the most commonly encountered (type E, 34\% of all collaterals). Type A epimyocardial collaterals, originating from a high acute marginal branch and inserting to the right posterolateral artery or originating from a lower acute marginal branch and inserting to the posterior descending artery, were the next most frequently observed connection (21\% of all collaterals). Type B collaterals (connecting distal ends of higher and lower acute marginal branches) represented $19 \%$ of all collaterals. Type D collaterals (originating from the proximal RCA and inserting in the posterolateral branch) and the morphologically similar type $\mathrm{C}$ collaterals (originating in the proximal RCA and inserting close to the posterior descending/posterolateral branch bifurcation) represented $17 \%$ and $9 \%$ of all collaterals, respectively. The main conclusion and practical implication from this classification is that type B collaterals appear to be the least

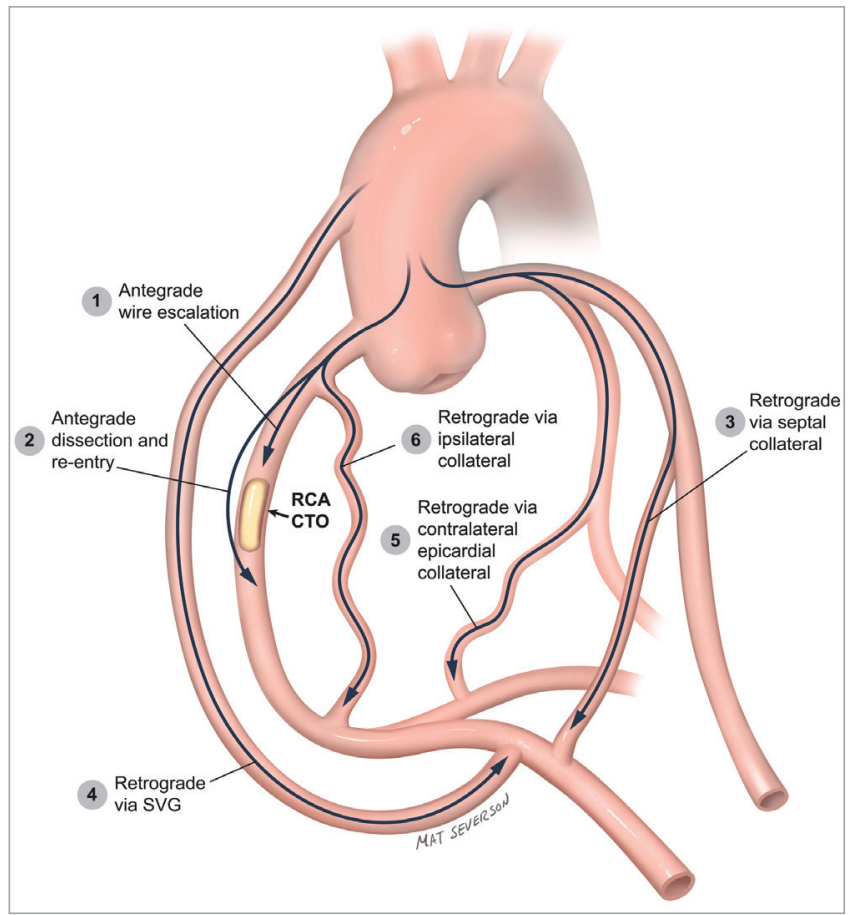

Figure 1. Crossing options for patients with right coronary artery chronic total occlusions.

suitable for the retrograde approach because of small size and high tortuosity, increasing the risk of injury and rupture, and they should therefore be avoided.

Fourth, crossing of ipsilateral RCA collaterals may be best attempted with a Sion ${ }^{\mathrm{TM}}$ guidewire (ASAHI Intecc), as is standard for most retrograde procedures currently.

Fifth, the microcatheter may need to be changed during collateral crossing attempts when trying to achieve a balance between crossability (with the NHancerTM; IMDS, Roden, The Netherlands) and support (with the Corsair).

Sixth, avoiding guidewire externalisation may minimise the risk of collateral vessel injury by minimising the shear tension applied to the collateral. Alternatives to externalisation are the use of the retrograde guidewire as a marker for antegrade crossing, or the use of the "tip-in" technique if retrograde guidewire crossing is achieved. In the "tip-in" technique ${ }^{20}$, the retrograde guidewire is advanced into an antegrade microcatheter that can then be tracked over the retrograde guidewire through the lesion, enabling antegrade wiring and stenting ${ }^{20}$. This is easier to achieve when the retrograde guidewire enters the antegrade guide catheter, but can also be performed within the proximal portion of the CTO vessel segment.

Seventh, if externalisation is pursued, it can be facilitated by use of a second guide catheter in a "ping-pong" fashion, alternating engagement of the RCA with the "retrograde" guide catheter (through which the retrograde guidewire is advanced) and the "antegrade" guide catheter (that receives the retrograde guidewire after CTO crossing). 
Using the above techniques Mashayekhi et al successfully treated eight of nine attempted lesions, achieving an overall phenomenal success rate of $94 \%$ for RCA CTOs.

Who should perform ipsilateral collateral retrograde RCA CTO PCI? This is clearly not a procedure for the novice CTO operator, or even the novice retrograde operator. It should be performed by expert operators with extensive experience in retrograde CTO PCI and advanced technical skills. Moreover, it should be performed at centres that can treat potential complications, such as epicardial vessel perforation. Such centres should have equipment for sealing perforations, such as coils ${ }^{21}$, microparticles, or thrombin ${ }^{14}$, and access to cardiac surgery. Epicardial vessel perforation may require treatment from both sides of the perforation that could be challenging if the CTO has not been successfully recanalised ${ }^{22}$.

Recanalising RCA CTOs can be challenging, but can also provide important clinical benefits ${ }^{23}$. Having multiple crossing options (Figure 1) is critical for high success rates. Retrograde crossing via ipsilateral collaterals has a limited, yet important role in the quest to restore RCA patency. Our patients stand to derive the benefits from application of this elegant advance in retrograde CTO PCI.

\section{Conflict of interest statement}

E.S. Brilakis has received consulting/speaker honoraria from Abbott Vascular, ASAHI, Boston Scientific, Elsevier, Somahlution, St. Jude Medical and Terumo, and research support from Infraredx and Boston Scientific. His spouse is an employee of Medtronic. W.J. Nicholson has received consulting/speaker honoraria from Abbott Vascular, ASAHI, Boston Scientific and Edwards Lifesciences, and intellectual property royalties from Vascular Solutions.

\section{References}

1. Morino Y, Kimura T, Hayashi Y, Muramatsu T, Ochiai M, Noguchi Y, Kato K, Shibata Y, Hiasa Y, Doi O, Yamashita T, Morimoto T, Abe M, Hinohara T, Mitsudo K; J-CTO Registry Investigators. In-hospital outcomes of contemporary percutaneous coronary intervention in patients with chronic total occlusion insights from the J-CTO Registry (Multicenter CTO Registry in Japan). JACC Cardiovasc Interv. 2010;3:143-51.

2. Galassi AR, Tomasello SD, Reifart N, Werner GS, Sianos G, Bonnier H, Sievert H, Ehladad S, Bufe A, Shofer J, Gershlick A, Hildick-Smith D, Escaned J, Erglis A, Sheiban I, Thuesen L, Serra A, Christiansen E, Buettner A, Costanzo L, Barrano G, Di Mario C. In-hospital outcomes of percutaneous coronary intervention in patients with chronic total occlusion: insights from the ERCTO (European Registry of Chronic Total Occlusion) registry. EuroIntervention. 2011;7:472-9.

3. Christopoulos G, Karmpaliotis D, Alaswad K, Yeh RW, Jaffer FA, Wyman RM, Lombardi WL, Menon RV, Grantham JA, Kandzari DE, Lembo N, Moses JW, Kirtane AJ, Parikh M, Green P, Finn M, Garcia S, Doing A, Patel M, Bahadorani J, Tarar MN, Christakopoulos GE, Thompson CA, Banerjee S, Brilakis ES.
Application and outcomes of a hybrid approach to chronic total occlusion percutaneous coronary intervention in a contemporary multicenter US registry. Int J Cardiol. 2015;198:222-8.

4. Widimsky P, Straka Z, Stros P, Jirasek K, Dvorak J, Votava J, Lisa L, Budesinsky T, Kolesar M, Vanek T, Brucek P. One-year coronary bypass graft patency: a randomized comparison between off-pump and on-pump surgery angiographic results of the PRAGUE-4 trial. Circulation. 2004;110:3418-23.

5. Goldman S, Zadina K, Moritz T, Ovitt T, Sethi G, Copeland JG, Thottapurathu L, Krasnicka B, Ellis N, Anderson RJ, Henderson W; VA Cooperative Study Group \#207/297/364. Long-term patency of saphenous vein and left internal mammary artery grafts after coronary artery bypass surgery: results from a Department of Veterans Affairs Cooperative Study. J Am Coll Cardiol. 2004;44:2149-56.

6. Brilakis ES, Grantham JA, Rinfret S, Wyman RM, Burke MN, Karmpaliotis D, Lembo N, Pershad A, Kandzari DE, Buller CE, DeMartini T, Lombardi WL, Thompson CA. A percutaneous treatment algorithm for crossing coronary chronic total occlusions. JACC Cardiovasc Interv. 2012;5:367-79.

7. Brilakis ES, Banerjee S, Lombardi WL. Retrograde recanalization of native coronary artery chronic occlusions via acutely occluded vein grafts. Catheter Cardiovasc Interv. 2010;75:109-13.

8. Brilakis ES, Grantham JA, Banerjee S. "Ping-pong" guide catheter technique for retrograde intervention of a chronic total occlusion through an ipsilateral collateral. Catheter Cardiovasc Interv. 2011;78:395-9.

9. Brilakis ES, Grantham JA, Thompson CA, DeMartini TJ, Prasad A, Sandhu GS, Banerjee S, Lombardi WL. The retrograde approach to coronary artery chronic total occlusions: a practical approach. Catheter Cardiovasc Interv. 2012;79:3-19.

10. Brilakis ES, ed. Manual of Coronary Chronic Total Occlusion Interventions. A Step-By-Step Approach. Waltham, MA, USA: Elsevier; 2013.

11. El Sabbagh A, Patel VG, Jeroudi OM, Michael TT, Alomar ME, Mogabgab O, Fuh E, Roesle M, Rangan BV, Abdullah S, Hastings JL, Grodin J, Kumbhani DJ, Alexopoulos D, Fasseas P, Banerjee S, Brilakis ES. Angiographic success and procedural complications in patients undergoing retrograde percutaneous coronary chronic total occlusion interventions: a weighted meta-analysis of 3,482 patients from 26 studies. Int J Cardiol. 2014;174:243-8.

12. Lo N, Michael TT, Moin D, Patel VG, Alomar M, Papayannis A, Cipher D, Abdullah SM, Banerjee S, Brilakis ES. Periprocedural myocardial injury in chronic total occlusion percutaneous interventions: a systematic cardiac biomarker evaluation study. JACC Cardiovasc Interv. 2014;7:47-54.

13. Werner GS, Coenen A, Tischer KH. Periprocedural ischaemia during recanalisation of chronic total coronary occlusions: the influence of the transcollateral retrograde approach. EuroIntervention. 2014; 10:799-805.

14. Kotsia AP, Brilakis ES, Karmpaliotis D. Thrombin injection for sealing epicardial collateral perforation during chronic total occlusion percutaneous coronary interventions. J Invasive Cardiol. 2014;26:E124-6. 
15. Christopoulos G, Karmpaliotis D, Wyman MR, Alaswad K, McCabe J, Lombardi WL, Grantham JA, Marso SP, Kotsia AP, Rangan BV, Garcia SA, Lembo N, Kandzari D, Lee J, Kalynych A, Carlson H, Thompson CA, Banerjee S, Brilakis ES. Percutaneous intervention of circumflex chronic total occlusions is associated with worse procedural outcomes: insights from a Multicentre US Registry. Can J Cardiol. 2014;30:1588-94.

16. Galassi AR, Sianos G, Werner GS, Escaned J, Tomasello SD, Boukhris M, Castaing M, Büttner JH, Bufe A, Kalnins A, Spratt JC, Garbo R, Hildick-Smith D, Elhadad S, Gagnor A, Lauer B, Bryniarski L, Christiansen EH, Thuesen L, Meyer-Geßner M, Goktekin O, Carlino M, Louvard Y, Lefèvre T, Lismanis A, Gelev VL, Serra A, Marzà F, Di Mario C, Reifart N; Euro CTO Club. Retrograde Recanalization of Chronic Total Occlusions in Europe: Procedural, In-Hospital, and Long-Term Outcomes From the Multicenter ERCTO Registry. J Am Coll Cardiol. 2015;65:2388-400.

17. Lin TH, Wu DK, Su HM, Chu CS, Voon WC, Lai WT, Sheu SH. Septum hematoma: a complication of retrograde wiring in chronic total occlusion. Int J Cardiol. 2006;113:e64-6.

18. Iturbe JM, Abdel-Karim AR, Raja VN, Rangan BV, Banerjee S, Brilakis ES. Use of the venture wire control catheter for the treatment of coronary artery chronic total occlusions. Catheter Cardiovasc Interv. 2010;76:936-41.
19. Mashayekhi K, Behnes M, Akin I, Kaiser T, Neuser H. Novel retrograde approach for percutaneous treatment of chronic total occlusions of the right coronary artery using ipsilateral collateral connections: a European centre experience. EuroIntervention. 2015;11:1231-6.

20. Vo MN, Ravandi A, Brilakis ES. "Tip-in” technique for retrograde chronic total occlusion revascularization. J Invasive Cardiol. 2015;27:E62-4.

21. Tarar MN, Christakopoulos GE, Brilakis ES. Successful management of a distal vessel perforation through a single 8-French guide catheter: Combining balloon inflation for bleeding control with coil embolization. Catheter Cardiovasc Interv. 2015;86:412-6.

22. Brilakis ES, Karmpaliotis D, Patel V, Banerjee S. Complications of chronic total occlusion angioplasty. Interventional Cardiology Clinics. 2012;1:373-89.

23. Christakopoulos GE, Christopoulos G, Carlino M, Jeroudi OM, Roesle M, Rangan BV, Abdullah S, Grodin J, Kumbhani DJ, Vo M, Luna M, Alaswad K, Karmpaliotis D, Rinfret S, Garcia S, Banerjee S, Brilakis ES. Meta-analysis of clinical outcomes of patients who underwent percutaneous coronary interventions for chronic total occlusions. Am $J$ Cardiol. 2015;115:1367-75. 